\title{
Superando el "síndrome del casillero vacío". Determinantes de la distribución del ingreso en América Latina
}

\author{
Ivonne González y Ricardo Martner
}

RESUMEN

La persistente desigualdad en América Latina parece reflejar la inexistencia de políticas específicas orientadas a disminuir esta brecha. El objetivo del presente trabajo es estimar mediante técnicas econométricas los determinantes de la distribución del ingreso en América Latina, en un contexto en que parecen coexistir el crecimiento económico y la reducción de las desigualdades, superando el "síndrome del casillero vacío" que caracterizó a la región en las décadas de 1980 y 1990. Con estudios de corte transversal en una muestra de países de la Organización de Cooperación y Desarrollo Económicos (OCDE) y de América Latina, y estimaciones de panel para 18 países latinoamericanos respecto del período 1990-2010, se muestra la relevancia de variables educacionales, institucionales y macroeconómicas en las mejoras recientes. Asimismo, se identifica la importancia de la acción fiscal, con variables como el gasto social, el gasto en educación, el gasto en capital y un indicador de progresividad tributaria.

PALABRAS CLAVE

CLASIFICACIÓN JEL

AUTORES
Distribución del ingreso, análisis económico, modelos econométricos, gastos públicos, tributación, política fiscal, crecimiento económico, America Latina, Caribe

I32, H3, E6, O5

Ivonne González es Asistente de Investigación en la División de Desarrollo Económico, CePAL, Naciones Unidas. ivonne.gonzalez@cepal.org

Ricardo Martner es Coordinador del área fiscal de la División de Desarrollo Económico, cepal, Naciones Unidas. ricardo.martner@cepal.org 


\section{I}

\section{Introducción}

América Latina sigue siendo la región más desigual del mundo, si bien la mayoría de sus países clasifican como economías de ingresos medios y continúan experimentando un crecimiento relativamente sostenido. Según proyecciones del Fondo Monetario Internacional (FMI, 2012), varios países rondarán un ingreso per cápita de 20.000 dólares a paridad del poder adquisitivo, cifra considerada de "país desarrollado". Y por tanto los desafíos serán aún mayores en materia de distribución de ingresos.

Ilustra esta desigualdad el habitual indicador que mide la distribución del ingreso: el coeficiente de Gini. La discusión sobre esta distribución es diferente de aquella respecto del crecimiento, si bien como se sabe pueden existir dilemas y complementariedades (CEPAL, 1990). Por ejemplo, Burundi tiene un producto interno bruto (PIB) nominal per cápita de 192 dólares, pero su coeficiente de Gini es de 0,33 , es decir, indica una distribución del ingreso mejor que la de uno de los países menos desiguales de América Latina, el Uruguay, cuyo coeficiente de Gini es de 0,42 y su PIB nominal per cápita de 12.000 dólares en el año 2010.

Coexisten en la región situaciones de crecimiento con mala distribución del ingreso (el caso de varios países latinoamericanos), de estancamiento o pobreza con buena y mala distribución del ingreso, pero también $-\mathrm{y}$ afortunadamente - de crecimiento con igualdad ${ }^{1}$. El "síndrome del casillero vacío" (Fajnzylber, 1990) evidencia que los países de América Latina no alcanzaron objetivos simultáneos de crecimiento y equidad durante la década de 1980, ni tampoco (premonitoriamente) en la década de 1990. Desde la publicación del artículo de referencia que da el título a este trabajo, la distribución del ingreso no ha mejorado significativamente en la región, pasando el coeficiente de Gini de 0,55 en 1990 a 0,50 en el 2010 como promedio. Esta persistencia de la desigualdad pareciera reflejar la inexistencia de políticas específicas que apunten a disminuir esta brecha, así como el predominio de la volatilidad de los niveles de ingresos y del empleo.

\footnotetext{
$\square$ El presente artículo es una actualización de González y Martner (2010).

${ }^{1}$ En los países de la OCDE, esta situación se dio con particular fuerza entre 1950 y 1980, bajando el coeficiente de Gini de más de 0,40 a 0,30, en un contexto de crecimiento económico (Afonso, Schuknecht y Tanzi, 2008).
}

La relación entre el nivel y la distribución del ingreso nacional tiene anverso: igualar para crecer, reverso: crecer para igualar, y dilemas y complementariedades (CEPAL, 2010). Existen muchos estudios en que se procura estimar la repercusión de la distribución del ingreso en el crecimiento, aunque en su mayoría los resultados son más bien indefinidos. Barro (2000) utiliza regresiones de panel para una muestra amplia de 100 países, con el propósito de estimar la tasa de crecimiento per cápita del PIB, cuyas variables explicativas son, entre otras, la tasa de inversión, la tasa de fertilidad, los años de escolaridad y los términos de intercambio. A estas se agrega el índice de Gini, variable que resulta no significativa para el total de la muestra, pero positiva en los países de menores ingresos y negativa en los de mayores recursos. El autor asimila este resultado a la existencia de una curva de Kuznets, en que "la desigualdad primero aumenta y luego decrece en el proceso de desarrollo económico".

Con posterioridad a este trabajo, la evidencia general confirma la falta de robustez estadística de esta relación (López y Servén, 2005). No parece existir, por lo tanto, una relación lineal verificable entre la distribución del ingreso y el crecimiento económico en estimaciones de corte transversal. Tampoco parece haber estudios que se limiten a una muestra de países de la región para estudiar el tema.

En la otra cara de la medalla, la discusión en torno de las causas de esta mala distribución del ingreso ha sido intensa y controvertida. Sin embargo, hay pocos estudios (si es que existe alguno con especial enfoque en América Latina) en que se procure identificar cuantitativamente los factores explicativos de esta situación. Destacan los trabajos de Martorano y Cornia (2011) y Cornia (2012), que han recopilado variables relacionadas con la distribución del ingreso para la región en una base de datos de acceso público, además de una amplia serie de investigaciones de Lustig, López-Calva y OrtizJuárez (2011) —quienes analizan casos seleccionados e identifican variadas causas en la caída reciente de las medidas de inequidad, como los progresos educativos y los aumentos en las transferencias del Estado a las familias más pobres - y de la Comisión Económica para América Latina y el Caribe (CEPAL, 2011), donde se descomponen las variaciones de la desigualdad en ingresos laborales y no laborales. 
En una estimación econométrica reciente para los países de la OCDE, Afonso, Schuknecht y Tanzi (2008) obtienen efectos positivos de las políticas públicas en la distribución del ingreso, directamente por la vía del gasto social e indirectamente por medio de la calidad de la educación y de las instituciones.

El presente artículo tiene como objeto replicar estas metodologías para los países de América Latina, examinando a través de estimaciones econométricas la repercusión, entre otras variables, del gasto público y de la composición de los impuestos en la distribución del ingreso. Esta aproximación es más simple que la utilizada habitualmente, en la que se comparan los coeficientes de Gini antes y después de impuestos y gastos públicos (para una recopilación, véase Gómez Sabaini y Martner, 2008), y se procura hacer una estimación directa de la acción fiscal sobre la distribución del ingreso en un conjunto amplio de países de la región. En tal sentido, puede ayudar a otorgarle consistencia a la literatura en que se enfatiza el papel preponderante de la acción fiscal en las variaciones del coeficiente de Gini.

Previo a ello, en la sección II se describen las tendencias recientes de la distribución del ingreso y del crecimiento; en la sección III se revisan algunos textos antiguos y recientes de la CEPAL en torno de las propuestas para superar el "síndrome del casillero vacío"; finalmente, y a modo de conclusión, en la sección IV se presentan las estimaciones realizadas.

\section{II}

\section{El "síndrome del casillero vacío"}

En las últimas décadas el crecimiento ha sido considerablemente volátil, con cuatro fases muy marcadas a partir de 1990 (véase el gráfico 1): la primera de expansión hasta 1997, la segunda fase de aguda crisis entre 1998 y 2002 , la tercera de pronunciada recuperación entre 2003 y 2008, y la cuarta fase, que comienza a fines de 2008 , de caída y rebote ante la crisis financiera internacional.
Sin olvidar la importancia de factores de carácter más estructural, estos marcados ciclos han tenido sin duda una gran incidencia en las variaciones de los coeficientes que miden la distribución del ingreso. En el cuadro 1 se observa que en varios países el coeficiente de Gini ha sido sensible a estas oscilaciones. Así, la década de 1990 podría calificarse como de "crecimiento

GRÁFICO 1

América Latina y el Caribe: crecimiento del PIB total, cuatro fases

(A precios constantes, tasas anuales de variación)

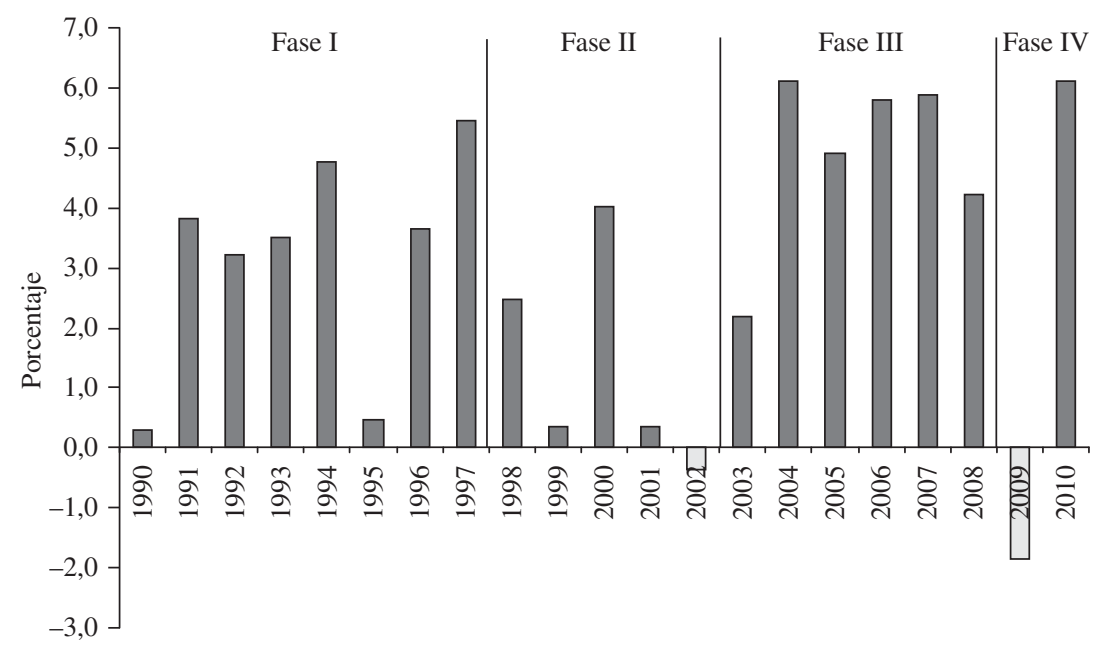

Fuente: elaboración propia sobre la base de datos oficiales de la Comisión Económica para América Latina y el Caribe (CEPAL). PIB: producto interno bruto. 
excluyente" (véase el gráfico 2), pues — con la excepción del Uruguay, Colombia y Honduras - el coeficiente de Gini se mantuvo constante en promedio, a pesar de un crecimiento anual cercano al $2 \%$ per cápita. Como podía esperarse, la crisis de 1998-2002 tendió a deteriorar dicho coeficiente, sobre todo en la Argentina y Costa Rica.

CUADRO 1

América Latina y el Caribe, países seleccionados: coeficiente de Gini (Valores entre 0 y 1 )

\begin{tabular}{|c|c|c|c|c|c|c|}
\hline País/Período & $1985-1990$ & $1990-1997$ & $1998-2002$ & $2003-2008$ & 2009 & 2010 \\
\hline Argentina & 0,50 & 0,52 & 0,55 & 0,53 & 0,51 & 0,51 \\
\hline Bolivia (Estado Plurinacional de) & 0,59 & 0,60 & 0,60 & 0,57 & - & - \\
\hline Brasil & 0,63 & 0,62 & 0,64 & 0,61 & 0,58 & - \\
\hline Chile & 0,56 & 0,55 & 0,56 & 0,54 & 0,52 & - \\
\hline Colombia & 0,59 & 0,57 & 0,58 & 0,57 & 0,58 & 0,58 \\
\hline Costa Rica & 0,45 & 0,45 & 0,48 & 0,48 & 0,50 & 0,49 \\
\hline Ecuador & 0,50 & 0,52 & 0,53 & 0,52 & 0,50 & 0,50 \\
\hline El Salvador & 0,50 & 0,51 & 0,52 & 0,49 & 0,48 & 0,45 \\
\hline Guatemala & 0,59 & 0,57 & 0,55 & 0,57 & - & - \\
\hline Honduras & 0,62 & 0,58 & 0,57 & 0,59 & 0,57 & 0,57 \\
\hline México & 0,54 & 0,53 & 0,53 & 0,52 & 0,48 & 0,48 \\
\hline Nicaragua & 0,57 & 0,58 & 0,58 & 0,54 & - & - \\
\hline Panamá & 0,52 & 0,57 & 0,55 & 0,54 & 0,52 & 0,52 \\
\hline Paraguay & 0,59 & 0,58 & 0,56 & 0,54 & 0,51 & 0,53 \\
\hline Perú & 0,49 & 0,53 & 0,54 & 0,50 & 0,47 & 0,46 \\
\hline República Dominicana & 0,50 & 0,52 & 0,53 & 0,56 & 0,57 & 0,55 \\
\hline Uruguay & 0,50 & 0,45 & 0,45 & 0,45 & 0,43 & 0,42 \\
\hline Venezuela (República Bolivariana de) & 0,50 & 0,49 & 0,50 & 0,45 & 0,42 & 0,39 \\
\hline América Latina (promedio simple) & 0,54 & 0,55 & 0,55 & 0,53 & 0,51 & 0,50 \\
\hline
\end{tabular}

Fuente: elaboración propia sobre la base de datos oficiales de la Comisión Económica para América Latina y el Caribe (CEPAL).

GRÁFICO 2

América Latina y el Caribe, países seleccionados: crecimiento del PIB por habitante y cambios en la desigualdad, 1990-2000

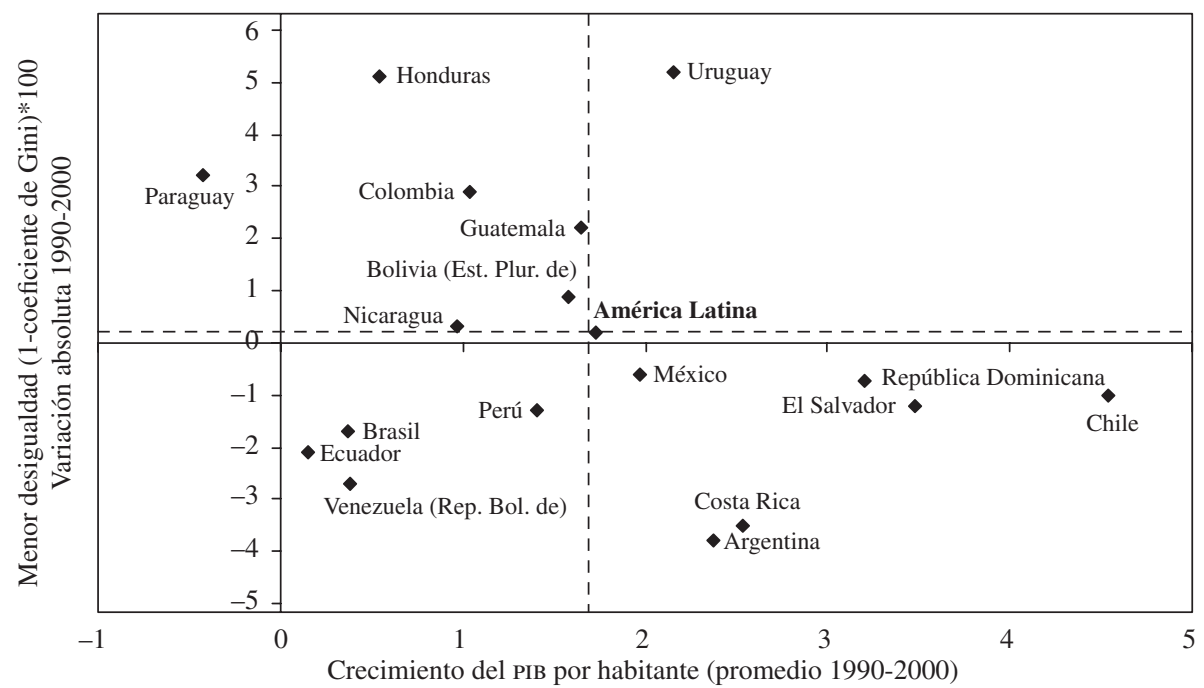

Fuente: elaboración propia sobre la base de datos oficiales de la Comisión Económica para América Latina y el Caribe (CEPAL). PIB: producto interno bruto. 
En cambio, la década del año 2000 puede caracterizarse retrospectivamente como de "crecimiento inclusivo", ya que — como se ilustra en el gráfico 3- la gran mayoría de los países de América Latina tuvieron un crecimiento positivo y mejoras sustantivas en su coeficiente de Gini, disminuyendo cuatro puntos en promedio. Aunque la evidencia es bastante reciente, merece subrayarse la coexistencia de crecimiento con grados crecientes de equidad, como se observa en la Argentina, Panamá, el Perú y el Uruguay, que crecieron por sobre la media y mejoraron su coeficiente de Gini sobrepasando el promedio.

Bolivia, el Brasil, El Salvador, México, Nicaragua y la República Bolivariana de Venezuela tuvieron avances significativos en la medición de distribución del ingreso, aunque sus economías crecieron menos que el promedio. Otros países, como el Ecuador y la República Dominicana experimentaron un pronunciado crecimiento, pero con cambios inferiores a la media en materia de distribución de ingresos. Por último, Chile, Colombia, Guatemala, Honduras y el Paraguay quedaron por debajo del promedio en crecimiento y en la variación absoluta del coeficiente de Gini. Por supuesto, estas medidas son estáticas y solo reflejan indicios de una dinámica económica y social que es cambiante. Lo que resulta claro es que la región se ha recuperado rápidamente de los efectos de la crisis financiera, y que existen avances muy disímiles en la distribución del ingreso, según los países.

Esta diversidad tal vez puede explicarse por la heterogeneidad productiva de la región. Cornia (2012) divide a los países en tres grupos: i) "economías industriales" (Argentina, Brasil, México, Uruguay); ii) "exportadores de materias primas" (Bolivia (Estado Plurinacional de), Chile, Colombia, Costa Rica, Ecuador, Perú y Venezuela (República Bolivariana de)), y iii) "receptores de remesas" (República Dominicana, El Salvador, Guatemala, Honduras, Nicaragua, Panamá y Paraguay). Aunque la clasificación es algo artificial y equívoca, tiene el mérito de mostrar diferencias significativas en la tendencia; las economías "industriales" y los exportadores de productos básicos (commodities) redujeron en mayor proporción sus índices de Gini que los países receptores de remesas (4 y 2 puntos del coeficiente de Gini, respectivamente; véase el gráfico 4 ).

Probablemente, existen otras situaciones específicas de cada país que permiten explicar estos progresos (véase el recuadro 1 para el caso del Brasil), pero sin duda vale la pena emprender estudios de inferencia estadística para identificar causas comunes.

GRÁFICO 3

América Latina y el Caribe, países seleccionados: crecimiento del PIB por habitante y cambios en la desigualdad, 2003-2010

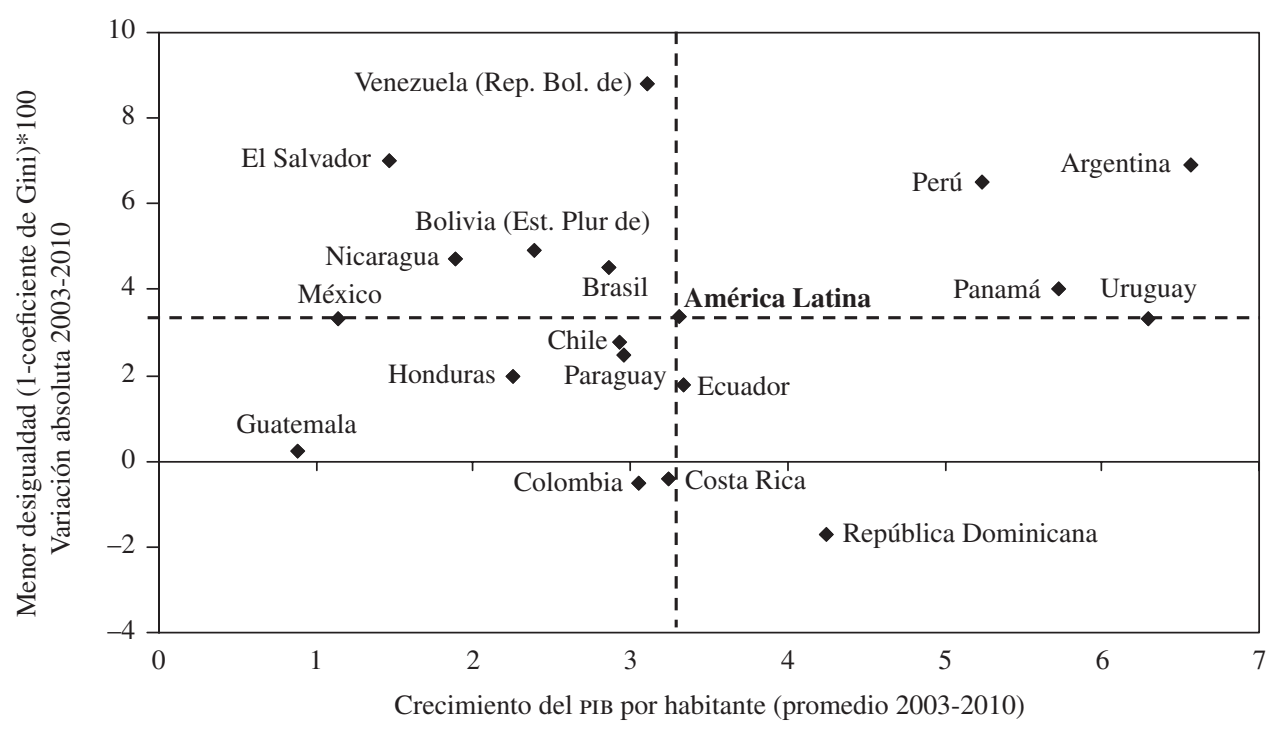

Fuente: elaboración propia sobre la base de datos oficiales de la Comisión Económica para América Latina y el Caribe (CEPAL).

PIB: producto interno bruto. 
RECUADRO 1

\section{La distribución del ingreso en el Brasil}

Después de décadas de estabilidad en torno de un 0,60, a partir del año 2000 el coeficiente de Gini pasó a una trayectoria de reducción de 0,7 puntos por año, llegando a 0,54 en 2008. Las evidencias disponibles indican que aproximadamente la mitad de la reducción se debió a mejoras del sistema de protección social, destacándose las contribuciones del programa Bolsa Familia (PBF) y de otros programas de asistencia social. En lo referente al PBF, hubo una ampliación considerable de las familias beneficiarias (hoy 11 millones de familias, o sea, casi 50 millones de individuos).

La segunda política fundamental para la reducción de las desigualdades fue la valorización del salario mínimo, que ha aumentado continuamente desde 1995. Conviene resaltar que, desde 2007, fue implementada una política de valorización del salario mínimo vigente hasta 2023, en que se prevén reajustes sobre la base de la inflación y el crecimiento del PIB de dos años antes. El salario mínimo indexa dos tercios de los beneficios de la seguridad social, tanto urbanos como rurales. Además de la red de protección social y de la recuperación del salario mínimo, la formalización creciente también contribuye a un mercado del trabajo cada vez más inclusivo. Finalmente, mejoras todavía lentas del perfil educacional de la población económicamente activa han contribuido a las reducciones de las desigualdades en el mercado laboral.

En el gráfico se aprecia el ritmo de la reducción continua esperada del coeficiente de Gini. Así, en 2015 el índice estaría por debajo del 0,50 según las metas establecidas en el Plan Plurianual (PPA) 2012-2015.

Brasil: coeficiente de Gini, 1995-2015

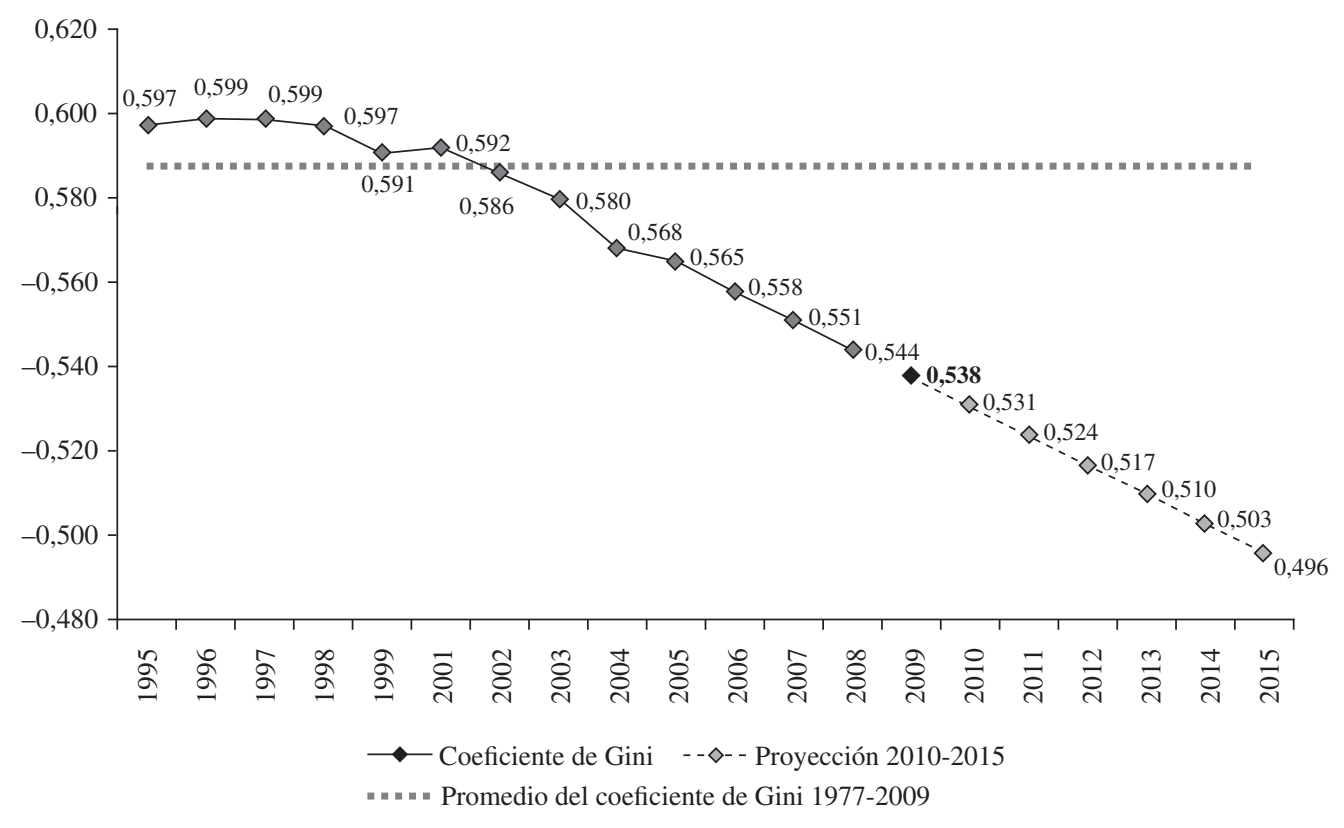

Fuente: Ministerio de Planificación, Presupuesto y Gestión, "Mensagem presidencial, Projeto de Lei Orçamentária - 2009”, Brasilia [en línea] http://www.planejamento.gov.br/secretarias/upload/Arquivos/sof/ploa09/080827_ploa_Mensagem09.pdf; y "Projeto de Lei do Plano Plurianual (PPA) 2012-2015 - Plano Mais Brasil”, Brasilia [en línea] http://www.planejamento.gov.br/noticia.asp?p=not\&cod=7571\&cat= $155 \& \sec =10$ 
GRÁFICO 4

América Latina y el Caribe: variación del índice de Gini

(Países agrupados según estructura económica)

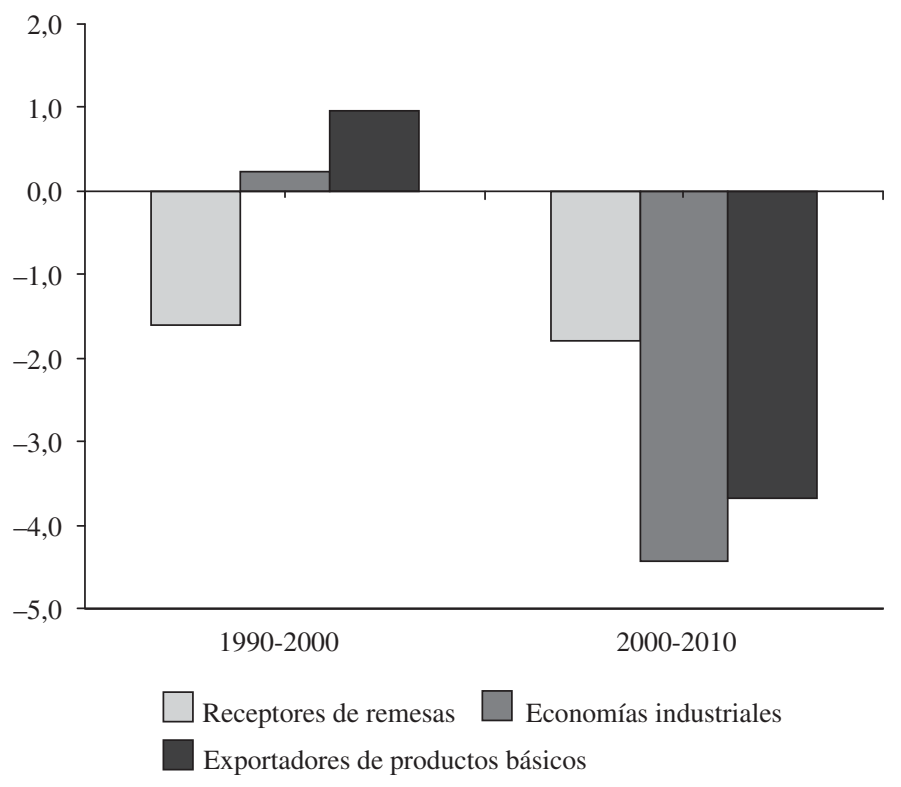

Fuente: elaboración propia sobre la base de datos oficiales de la Comisión Económica para América Latina y el Caribe (CEPAL) y G. Cornia (2012), "Inequality trends and their determinants: Latin America over 1990-2011", Working Papers, No WP2012/09, Instituto Mundial de Investigaciones de Economía del Desarrollo, 2012.

\section{III}

\section{Los determinantes de la distribución del ingreso}

La literatura sobre los determinantes de la distribución del ingreso es abundante y variada (Lerda, 2009). El Banco Mundial, en su Informe sobre el Desarrollo Mundial 2006, plantea que "La equidad se define en función de dos principios básicos. El primero es la igualdad de oportunidades, a saber, que los logros de una persona a lo largo de su vida deberían estar determinados fundamentalmente por sus propios talentos y esfuerzos, más que por circunstancias predeterminadas como la raza, el género, los antecedentes sociales y familiares o el país de nacimiento. El segundo principio es la ausencia de privación en los resultados, en particular en los terrenos de la salud, la educación y el consumo".

La CEPAL ha contribuido con diversos documentos al proceso de reflexión sobre lo que debe entenderse por equidad. Como lo recuerdan Infante y Sunkel (2009): "en CEPAL (1964) se postula que en esa época la heterogeneidad estructural de América Latina se manifestaba en los niveles diferentes de productividad de los ocupados en los distintos estratos productivos, lo que caracterizaba el funcionamiento económico de la región y además era el factor originario de la desigual distribución del ingreso". El concepto de convergencia productiva es entonces clave para el crecimiento económico con equidad, como se recalca en las publicaciones sucesivas de la CEPAL (2008 y 2010).

¿Por qué la distribución del ingreso es más equitativa en unos países que en otros? En conceptos como el "síndrome del casillero vacío" se recoge la incapacidad de la región, por muchas décadas, de abrir la "caja negra" del progreso técnico. Así, para Fajnzylber (1990) "Un sistema industrial competitivo internacionalmente, en un contexto social en que se ha superado un umbral mínimo de equidad (transformación agraria), puede tender a favorecer la equidad en el país correspondiente, por lo menos, por las siguientes vías: distribución 
relativamente más amplia de la propiedad, asociado a la creación de pequeñas y medianas empresas; difusión de la calificación de la mano de obra; crecimiento más rápido del empleo, asociado al dinamismo del mercado internacional; elevación de la productividad y de las remuneraciones; difusión del sistema educativo en una base social más amplia y más integrada, como requisito imprescindible para sostener la competitividad internacional, y, finalmente, difusión de la lógica industrial, tanto por vías formales como informales, al conjunto de la sociedad lo cual la hará más receptiva a absorber progreso técnico, factor que a su vez favorecerá la elevación de la productividad y, en esa medida, la difusión de los frutos del progreso técnico en forma más equitativa al conjunto de la sociedad" 2 .

Sin duda, esta visión de "convergencia productiva" es clave para entender las dinámicas de crecimiento con igualdad en países emergentes (Infante y Sunkel, 2009). Pero resulta interesante abordar más explícitamente los efectos de la estabilidad política, las instituciones y la política fiscal.

En el El pacto fiscal. Fortalezas, debilidades, desafíos (CEPAL, 1998) se señala que "la sociedad suele confiar al Estado un papel muy crucial en la promoción de la equidad, y el pacto fiscal resulta incompleto e insatisfactorio si ese papel se omite, se descuida o se cumple insuficientemente. Aquí resultan de importancia tareas de promoción de la igualdad de oportunidades, con sus expresiones, por ejemplo, en el ámbito de la educación, la salud y el empleo, y tareas de protección a poblaciones vulnerables", y se agrega a continuación que "no puede quedar descuidada la equidad con que se recaudan los recursos que el Fisco emplea para éstas y para sus demás tareas".

En CEPAL (2000) la equidad es vista como "el eje principal en torno del cual se requiere reorientar los patrones de desarrollo de la región" y "la vara fundamental para medir la calidad del desarrollo", siendo caracterizada como "la reducción de la desigualdad social en sus múltiples manifestaciones”. Esta visión del tema destaca por su amplitud conceptual, con lo que abre paso a múltiples posibilidades de intervención pública para asegurar mejores estándares de equidad, como lo ilustra el siguiente pasaje: “...las fuentes de las desigualdades se encuentran en distintos ámbitos de la vida social y económica y, por lo mismo, las intervenciones en pro de la equidad deben contemplar esta variedad de ámbitos.

\footnotetext{
2 Texto extraído de Torres (2006, pág. 347).
}

Por tal razón, es importante ampliar la noción de equidad considerando distintos aspectos que tienen que ver con la igualdad de oportunidades al inicio y en las trayectorias de los ciclos educativos y del empleo; con la igualdad de oportunidades para acceder al bienestar material, pero también para participar en decisiones y en el espacio público; con la igualdad de oportunidades para acceder a los sistemas de justicia, a la seguridad ciudadana y a estilos de vida saludables y con la igualdad de oportunidades para acceder a múltiples fuentes de conocimiento e información y a redes de apoyo social y de otra índole".

En CEPAL (2010) se plantea que "para abordar el desafío de la igualdad en forma cabal, la región debe transitar desde enfoques más "minimalistas" de Estado social y política social que predominaron en los años noventa y avanzar hacia la construcción de una red de protección y promoción social universal básica que se integre al modelo de desarrollo como pieza estructural, no residual".

A fin de cuentas, la distribución de ingresos es solo una arista de este concepto más amplio de igualdad, que engloba la provisión de múltiples bienes y servicios públicos cuya demanda y volumen dependerán, en sociedades democráticas, del voto mayoritario y de la construcción de mecanismos comunitarios de consenso. Musgrave y Buchanan (1999) plantean que la cuestión de la "decisión pública" (fiscal choice) es parte inherente del proceso fiscal, asunto que tiende a olvidar la tecnocracia especializada.

Afonso, Schuknecht y Tanzi (2008) sostienen que en un momento dado, en un país dado, la distribución del ingreso "primaria" (previa a la intervención del Estado) estaría determinada por los siguientes factores:

i) La herencia de la riqueza tangible y material.

ii) La herencia de capital humano, incluida una infinidad de activos que determinan el capital social de una persona.

iii) Normas y costumbres societales, incluidos sistemas explícitos e implícitos de castas y tribus y de matrimonios de similar riqueza o capital social.

iv) Las políticas públicas pasadas.

A esa lista los autores citados le agregan el "talento individual", que por cierto, tomado aisladamente, ha hecho ricos a pocos individuos. Importa más destacar la preponderancia de factores hereditarios, que no se pueden cambiar en el corto plazo y que tienen que ver esencialmente con la posición social inicial de los individuos en la sociedad. Si la equidad se define por igualdad de oportunidades, es claro que la distribución previa del ingreso es un importante factor explicativo del valor actual 
del coeficiente de Gini. Las políticas pasadas también han modificado las condiciones iniciales, si bien no es sencillo aislar dichas políticas de las políticas actuales en la distribución del ingreso, ni tampoco las políticas públicas pasadas de los cambios societales.

La persistencia presentada por los indicadores de desigualdad puede reflejar la inexistencia de políticas capaces de modificar esta situación, pero también proviene de una desigual distribución de los activos, tanto físicos como humanos. Por ejemplo, en el trabajo de Deininger y Olinto (2000) se encuentra que el coeficiente de Gini para la distribución de la tierra era de un 0,81 para América Latina, coeficiente que a nivel mundial solo llega a un 0,60. En el caso de la distribución de los años de escolaridad, el coeficiente de Gini es de un 0,42 comparado con un 0,27 de los países industrializados. Estos resultados son corroborados en el estudio de De Ferranti y otros (2004), quienes encontraron que la corelación existente entre el coeficiente de desigualdad y los años de escolaridad es de un 0,75, y con respecto a la distribución de la tierra es de un 0,5 para la región.

Otro factor explicativo se relaciona directamente con el mercado del trabajo en su capacidad de agregar movilidad social, lo que también se vincula con la demanda de empleo y por lo tanto con el nivel de actividad. El nivel de desempleo (o la tasa de empleo) y el PIB son asimismo importantes factores explicativos del cambio en la distribución del ingreso. Existe así un posible vínculo entre el nivel de ingresos y su distribución, pues la cantidad y la calidad de la provisión de bienes y servicios públicos dependerán de la capacidad de recaudación (cuyo principal determinante es el nivel de ingresos).

Es un hecho que la intervención del Estado - a través del nivel y la estructura impositiva, las políticas de gasto y las regulaciones - tiene una incidencia significativa en el coeficiente de Gini. De este modo en la OCDE, el coeficiente de Gini antes de impuestos y transferencias es de 0,45 , pasando a 0,31 luego de la acción redistributiva directa del Estado (que incluye la progresividad del sistema tributario, un tercio del efecto y las transferencias monetarias a los grupos de menores ingresos) (OCDE, 2008). Solo por estos conceptos la capacidad correctiva de la distribución primaria del ingreso por medio de la acción fiscal es tremendamente significativa.

En el caso de América Latina y con respecto al gasto público, mecanismos como las transferencias condicionadas — con que se procura mejorar la inclusión de los sectores más vulnerables-deberían tener un papel relevante como factor explicativo de los cambios en el coeficiente de Gini, aunque su volumen actual está lejos de incidir significativamente (CEPAL, 2011).
También la provisión de bienes públicos genera efectos indirectos y de más largo plazo, puesto que las políticas públicas que inciden en la productividad de los más pobres tienen retornos en materia de equidad. Nadie podrá dudar de que los gastos públicos en justicia, seguridad ciudadana, infraestructura y transporte público, salud, capacitación laboral, inclusión social, y tantos otros, benefician más que proporcionalmente a los más pobres al permitirles insertarse en la fuerza laboral en mejores condiciones.

El nivel de impuestos y su progresividad repercuten directamente en la distribución del ingreso. La capacidad del sistema tributario para corregir distribuciones desiguales dependerá del volumen recaudado y de la estructura de tasas según niveles de ingresos, pero también de la evasión del impuesto a la renta y del número de exenciones. A mediano plazo, el sistema tributario también puede influir en la oferta de trabajo (por ejemplo, si existen muchas cargas vinculadas al empleador), el esfuerzo individual y el tamaño de las familias, asuntos todos que inciden en la evolución del coeficiente de Gini.

\section{La evidencia empírica}

Fajnzylber (1990) utiliza en su trabajo la razón entre el quintil más rico (10\%) y los quintiles más pobres (40\%), como variable sustitutiva (proxy) de desigualdad; pero el indicador más ampliamente empleado en los estudios relacionados con la distribución del ingreso es el coeficiente de Gini. Dada la escasez y heterogeneidad de datos alternativos para los países de América Latina, se utilizará este último indicador en el desarrollo de las estimaciones (véase el recuadro 2).

En el estudio de Afonso, Schuknecht y Tanzi (2008) para países de la $\mathrm{OCDE}^{3}$ se presenta un interesante marco de análisis para replicar en los países latinoamericanos. El punto de inicio es una estimación de corte transversal, en que se incluye tanto a los países de la oCDE como a los de América Latina y el Caribe (véase detalle en el cuadro 2) respecto de los años 2000 y 2006. En una segunda etapa, el análisis se centra en una estimación de datos de panel para la muestra de América Latina y el Caribe, a objeto de precisar el efecto específico en la región de los determinantes identificados. Se utilizan variables fiscales, macroeconómicas, sociales e institucionales, desagregadas de acuerdo con el requerimiento

\footnotetext{
${ }^{3}$ Se agradece a estos autores por haber proporcionado sus bases de datos para este trabajo.
} 
RECUADRO 2

\section{Definición del coeficiente de Gini}

El coeficiente de Gini se define sobre la base de la curva de Lorenz, que describe el porcentaje acumulado del ingreso total que le pertenece al porcentaje más pobre de la población.

Se calcula como el cuociente entre el área comprendida entre la diagonal y la curva de Lorenz (área A en el gráfico) sobre el área bajo la diagonal (área A+B). Si existiera perfecta igualdad, la curva de Lorenz coincidiría con la diagonal, el área A desaparecería y el índice de Gini se haría 0, indicando ausencia de desigualdad. En el otro caso extremo, si existiera desigualdad total (es decir, una situación donde todo el ingreso fuera propiedad de una sola persona) la curva de Lorenz coincidiría con los ejes, el área B desaparecería y el coeficiente de Gini se haría 1, indicando desigualdad total.

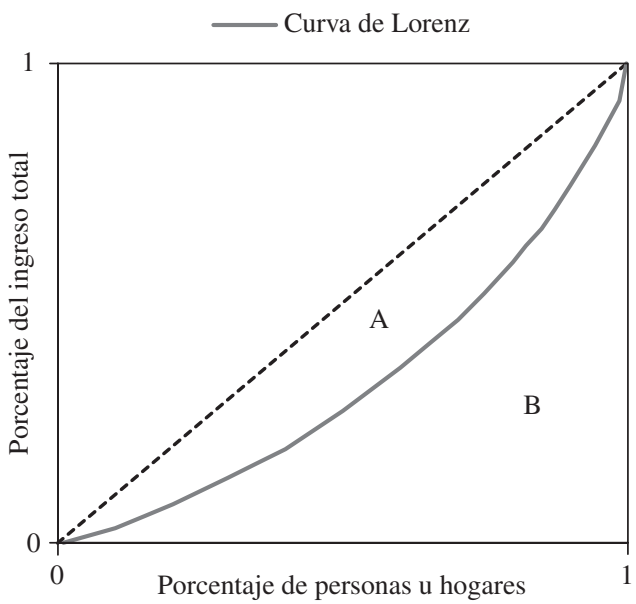

Fuente: elaboración propia.

CUADRO 2

Muestras seleccionadas, período 1990-2010

\begin{tabular}{ll}
\hline Región & Países incluidos en cada muestra \\
\hline América Latina y el Caribe (18 países) & Argentina, Bolivia (Estado Plurinacional de), Brasil, Chile, Colombia, Costa Rica, Ecuador, \\
& $\begin{array}{l}\text { El Salvador, Guatemala, Honduras, México, Nicaragua, Panamá, Paraguay, Perú, República } \\
\text { Dominicana, Uruguay y Venezuela (República Bolivariana de) }\end{array}$
\end{tabular}

Organización de Cooperación y Desarrollo Económicos (OCDE) (27 países)
Alemania, Austria, Bélgica, Dinamarca, España, Finlandia, Francia, Grecia, Holanda, Hungría, Irlanda, Italia, Luxemburgo, Noruega, Polonia, Portugal, Reino Unido de Gran Bretaña e Irlanda del Norte, República Eslovaca, República Checa, Suecia, Suiza, Canadá, Estados Unidos de América, Australia, Japón, Nueva Zelandia, República de Corea

Fuente: elaboración propia.

del análisis. Estas estimaciones se realizan para el período 1990-2010.

Como se detalla en el cuadro 3, las variables consideradas son fiscales (gasto público total, gasto público social, gasto público en educación, transferencias y subsidios corrientes, gastos de capital, ingresos tributarios, ingresos tributarios directos, impuestos sobre la renta, impuestos sobre la propiedad, ingresos tributarios indirectos, impuestos generales sobre bienes y servicios, indicador de progresividad tributaria); sociales (tasa neta de matrícula secundaria, logros en educación -indicadores del Programa Internacional de Evaluación de 
CUADRO 3

\section{Descripción y fuentes de variables utilizadas}

\begin{tabular}{lll}
\hline Variables & Descripción & Fuente \\
\hline Coeficiente de Gini & Índice de desigualdad, valores entre 0 y1 & CEPALSTAT (ALC) \\
& & Base de datos de la ocDE \\
Distribución de ingreso inicial & Coeficiente de Gini, año 1970 del Banco Mundial & Base de datos del Banco Mundial
\end{tabular}

Fiscales

\section{Gasto público total}

Gasto social

Transferencias y subsidios

Gasto público de capital

Impuestos sobre la renta

Impuestos sobre la propiedad

Impuestos generales sobre bienes y servicios

Indicador de progresividad tributaria
Gasto público total sobre el PIB (porcentaje)

Gasto público social sobre el PIB (porcentaje) (sin considerar gasto social en educación)

Transferencias y subsidios corrientes sobre el PIB (porcentaje)

Gasto público de capital sobre el PIB (porcentaje)

Recaudación de impuestos sobre la renta sobre el PIB (porcentaje)

Recaudación de impuestos a la propiedad sobre el PIB (porcentaje)

Recaudación de impuestos generales bienes y servicios sobre el PIB (porcentaje)

Recaudación de impuestos directos sobre indirectos
CEPALSTAT (América Latina)

Base de datos del Banco Mundial

CEPALSTAT (ALC)

Base de datos del Banco Mundial

CEPALSTAT (ALC)

Base de datos del Banco Mundial

CEPALSTAT (ALC)

CEPALSTAT (ALC)

oCDE Revenue Statistics

CEPALSTAT (ALC)

oCDE Revenue Statistics

CEPALSTAT (ALC)

oCDE Revenue Statistics

Construcción propia sobre la base de datos de

CEPALSTAT (ALC) y ocDE Revenue Statistics

Educación

Gasto público en educación

Tasa de matrícula secundaria

Medición de calidad: indicador

Programa Internacional de

Evaluación de Estudiantes (PISA)

Índice de capital humano

Años de escolaridad
Gasto público en educación sobre PIB (porcentaje)

Tasa neta de matrícula secundaria (porcentaje)

Indicador: PISA
CEPALSTAT (ALC)

Base de datos del Banco Mundial

Base de datos del Banco Mundial

OCDE PISA database

Adultos con educación terciaria y secundaria sobre adultos con educación primaria (población entre 25 y 65 años)

Años de educación formal en población adulta (entre 25 a 65 años)

Martorano y Cornia (2011)

Martorano y Cornia (2011)

Institucionales

Índice de estabilidad pública

Efectividad gubernamental

Voz y rendición de cuentas
$(1 / 2)^{*}$ Estabilidad política+(1/2)*Estado de derecho Indice de efectividad gubernamental Índice de voz y rendición de cuentas, que mide derechos civiles, humanos y políticos
Base de datos Worldwide Governance Indicators Base de datos Worldwide Governance Indicators Base de datos Worldwide Governance Indicators

\section{Macroeconómicas}

Ingreso per cápita a PPA

Tasa de desempleo

Tipo de cambio real (TCR)

Índice de precios
Ingreso por habitante a paridad del poder adquisitivo (variación anual, porcentaje)

Tasa anual media (porcentaje)

TCR (índice)

Variación del índice de precios al consumidor (IPC), promedio anual
Base de datos del Banco Mundial

CEPALSTAT

Base de datos del Banco Mundial

CEPALSTAT (ALC)

CEPALSTAT (ALC)

Fuente: elaboración propia.

PISA: Programa Internacional de Evaluación de Estudiantes.

PPA: Paridad de poder adquisitivo. 
Estudiantes (PISA por sus siglas en inglés)—, distribución de ingreso inicial); macroeconómicas (ingreso per cápita a paridad del poder adquisitivo, ingreso per cápita inicial, tasa de desempleo, inflación, tasa de crecimiento del PIB) e institucionales.

\section{Regresiones de corte transversal: resultados para la OCDE y América Latina y el Caribe}

En el cuadro 4 se presenta un resumen de las regresiones de corte transversal estimadas. Las ecuaciones de
Afonso, Schuknecht y Tanzi (2008), estimadas para 22 países de la OCDE, se extienden a los países de América Latina y el Caribe que contaban con índices PISA en el año 2000 (ecuaciones (1') y (2')). Luego, con la nueva muestra, se replica el ejercicio para el año 2006 a fin de detectar eventuales quiebres, y finalmente en la ecuación (3') se incluyen los 18 países de América Latina y el Caribe, reemplazando los índices PISA por la tasa neta de matrículas de educación secundaria (variable que no indica calidad, como en el caso anterior, sino cobertura del sistema educacional).

CUADRO 4 OCDE y América Latina y el Caribe: determinantes
de la distribución del ingreso, 2000-2006

\begin{tabular}{|c|c|c|c|c|c|c|c|}
\hline Variable dependiente & \multicolumn{7}{|c|}{ Coeficiente de Gini } \\
\hline Muestra & \multicolumn{2}{|c|}{$\mathrm{OCDE}^{\mathrm{a}}$} & \multicolumn{2}{|c|}{ ALC y OCDE (en logaritmo) } & \multicolumn{3}{|c|}{ ALC y OCDE (en logaritmo) } \\
\hline Período & \multicolumn{2}{|c|}{2000} & \multicolumn{2}{|c|}{2000} & \multicolumn{3}{|c|}{2006} \\
\hline Ecuaciones & (1) & (2) & $\left(1^{\prime}\right)$ & $\left(2^{\prime}\right)$ & $\left(1^{\prime}\right)$ & $\left(2^{\prime}\right)$ & $\left(3^{\prime}\right)$ \\
\hline \multicolumn{8}{|l|}{ Variables independientes } \\
\hline Transferencias y subsidios /PIB & $\begin{array}{l}-7,13 * * * \\
(-3,93)\end{array}$ & & $\begin{array}{l}-0,34 * * * \\
(-3,27)\end{array}$ & & $\begin{array}{l}-0,26 * * \\
(-2,38)\end{array}$ & & \\
\hline Gasto social $/ \mathrm{PIB}^{\mathrm{b}}$ & & $\begin{array}{l}-2,51 \text { **** } \\
(-4,10)\end{array}$ & & $\begin{array}{l}-0,086 \text { *** } \\
(-3,30)\end{array}$ & & $\begin{array}{l}-0,22^{* * * *} \\
(-3,08)\end{array}$ & $\begin{array}{c}-0,13 * \\
(-1,89)\end{array}$ \\
\hline Impuesto sobre el ingreso personal/PIB & $\begin{array}{l}-1,51 \\
(-1,17)\end{array}$ & & $\begin{array}{l}-0,15 \text { *** } \\
(-2,47)\end{array}$ & & $\begin{array}{c}-0,066 \\
(-1,04)\end{array}$ & & \\
\hline Índice PISA total (logros en educación) ${ }^{\mathrm{c}}$ & $\begin{array}{l}-0,86^{* * * *} \\
(-2,92)\end{array}$ & & $\begin{array}{l}-1,32 * * * \\
(-3,99)\end{array}$ & & $\begin{array}{l}-1,64 * * * \\
(-4,30)\end{array}$ & & \\
\hline Índice PISA (resolución de problemas) ${ }^{\mathrm{c}}$ & & $\begin{array}{l}-0,90^{* * * *} \\
(-6,13)\end{array}$ & & $\begin{array}{l}-1,25^{* * *} \\
(-5,74)\end{array}$ & & $\begin{array}{l}-0,80 \text { ** } \\
(-2,60)\end{array}$ & \\
\hline Coeficiente de Gini 1970 & & $\begin{array}{l}0,47 * * * \\
(4,85)\end{array}$ & & $\begin{array}{l}0,50 * * * \\
(6,19)\end{array}$ & & $\begin{array}{l}0,45 * * * \\
(3,57)\end{array}$ & ${ }^{0,77 * * *}$ \\
\hline Gasto público en educación /PIB & & & & & & & $\begin{array}{c}-0,08 \\
(-0,12)\end{array}$ \\
\hline Matrícula educación secundaria & & & & & & & $\begin{array}{c}-0,22 \\
(-0,91)\end{array}$ \\
\hline $\mathrm{N}^{\mathrm{o}}$ de observaciones & 22 & 11 & 27 & 16 & 31 & 18 & 31 \\
\hline $\mathbf{R}^{2}$ ajustado & 0,56 & 0,92 & 0,86 & 0,98 & $\mathbf{0 , 7 3}$ & 0,93 & 0,93 \\
\hline
\end{tabular}

Fuente: elaboración propia.

Nota: Valores estadísticamente significativos al 1\%***, 5\%** y 10\%*. Estadístico T entre paréntesis.

a Resultados consignados en trabajo de Afonso, Schuknecht y Tanzi (2008).

b En el gasto social no se incluye el gasto en educación.

c Índice PISA para América Latina incluye resultados solo para la Argentina, el Brasil, Chile, México y el Uruguay.

OCDE: Organización de Cooperación y Desarrollo Económicos.

ALC: América Latina y el Caribe.

PIB: producto interno bruto.

PISA: Programa Internacional de Evaluación de Estudiantes. 
En el trabajo de Afonso, Schuknecht y Tanzi (2008), las transferencias y subsidios y el gasto social, alternativamente, son variables altamente significativas, así como el coeficiente de distribución inicial (coeficiente de Gini de 1970) y los logros en educación, medidos a través del indicador PISA agregado, y más aún el específico de "resolver problemas". Las variables de institucionalidad no resultaron significativas, como tampoco variables de control como el ingreso por habitante y el desempleo. El impuesto sobre el ingreso personal tampoco se reveló significativo.

La ampliación de esta muestra a algunos países de América Latina y el Caribe — aquellos en que se emplea la medición PISA — entrega resultados muy similares. En la primera especificación, con transferencias y subsidios como variable explicativa (ecuación (1')), resultan significativas las variables de impuesto sobre la renta personal (al menos para el año 2000) y los logros en educación. Cuando se utiliza el gasto social agregado (ecuación (2')), este resulta significativo solo para el año 2006, a la vez que se diluye el efecto de la variable tributaria, probablemente debido a problemas de multicolinealidad.
Las regresiones tienden a ser fuertemente dependientes de la variable autorregresiva del coeficiente de Gini inicial. En cualquier caso, el mayor efecto resulta de las variables relacionadas con educación.

En el gráfico 5 se ilustra la estrecha alineación en torno de la recta de regresión entre el coeficiente de Gini y la medición PISA, y se muestra además el marcado retraso de los niveles educacionales en los países de América Latina. Ello se refleja, para los estudiantes de 15 años que dieron las pruebas PISA en la región, en una diferencia promedio cercana a dos años de escolarización con respecto a la República de Corea y Finlandia (OCDE/CEPAL, 2011).

A continuación se ilustran gráficamente otras correlaciones parciales relevantes en los gráficos 6 y 7 .

En una segunda etapa se procuró incluir en la muestra a los 18 países de América Latina (véase la ecuación (3')), observándose un deterioro de la calidad del ajuste estadístico al resultar no significativas la nuevas variables consideradas, lo que se puede explicar sobre todo por la carencia de un indicador adecuado de calidad de la educación para la región.

GRÁFICO 5

América Latina (países seleccionados) y OCDE: coeficiente de Gini e índice PISA

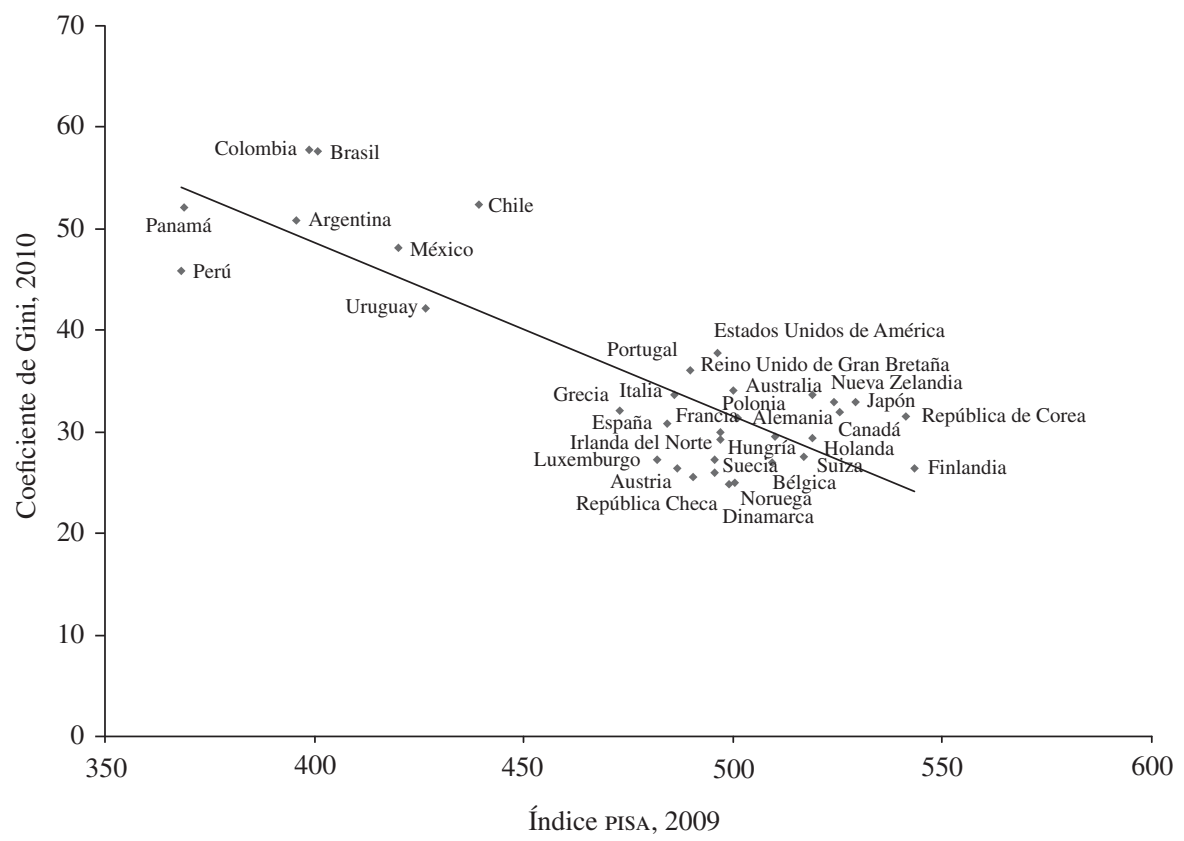

Fuente: elaboración propia, sobre la base de Organización de Cooperación y Desarrollo Económicos (OCDE), a partir de "Database - PISA 2009", OECD [en línea] http://pisa2009.acer.edu.au/

PISA: Programa Internacional de Evaluación de Estudiantes. 
GRÁFICO 6

\section{América Latina y el Caribe (países seleccionados) y OCDE: coeficiente de Gini y gasto social}

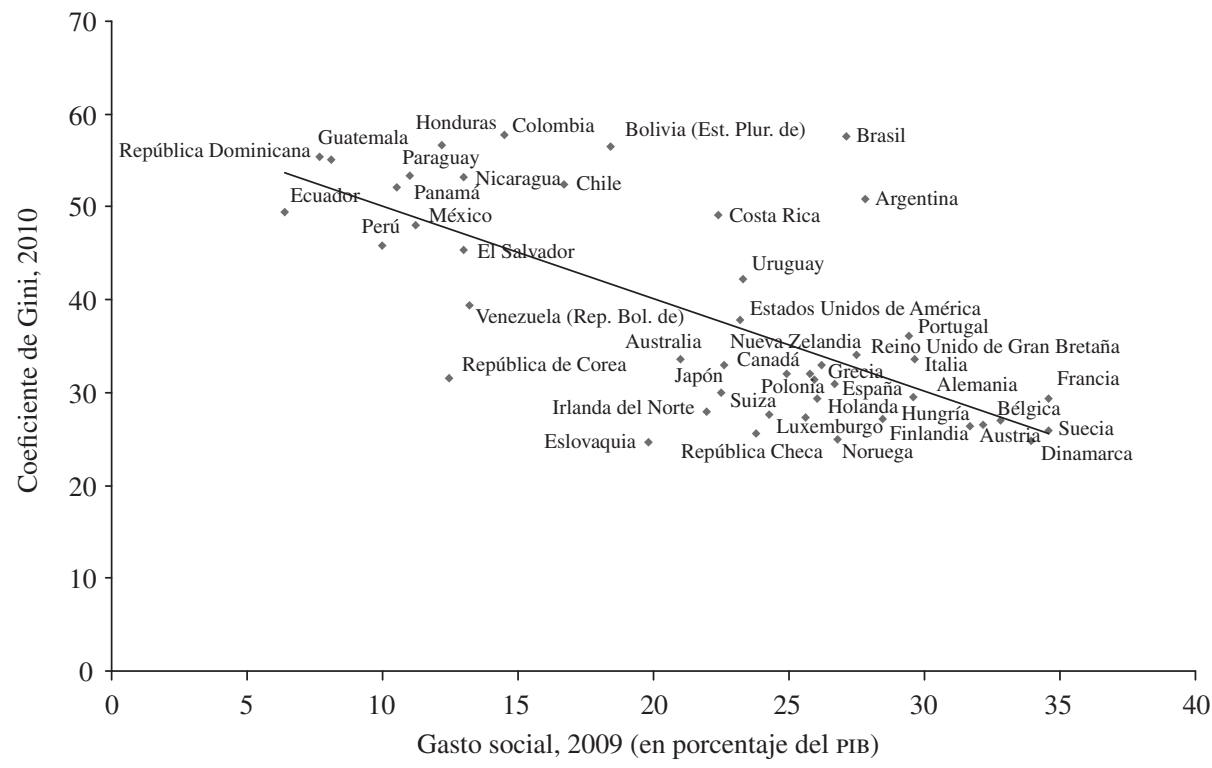

Fuente: elaboración propia sobre la base de datos oficiales de la Comisión Económica para América Latina y el Caribe (CEPAL) para países de América Latina y el Caribe y OECD.STAT para países de la OCDE.

PIB: producto interno bruto.

GRÁFICO 7

\section{América Latina y el Caribe (países seleccionados) y OCDE: coeficiente de Gini e índice de progresividad tributaria}

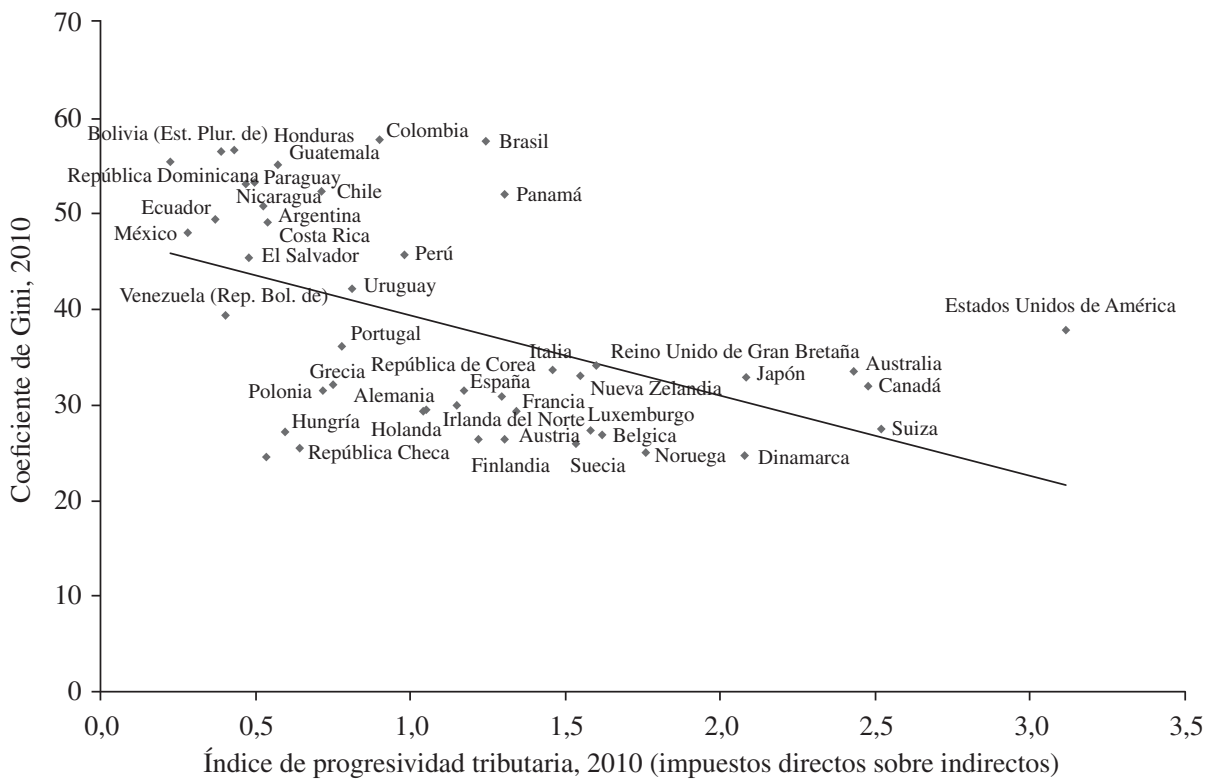

Fuente: elaboración propia sobre la base de datos oficiales de la Comisión Económica para América Latina y el Caribe (CEPAL) para países de América Latina y el Caribe y de la Organización de Cooperación y Desarrollo Económicos (OCDE) (2011), Revenue Statistics 1965-2010, 2011 para países de la OCDE. 
Aunque los resultados señalados son reveladores, también es pertinente enfocar el análisis en países de América Latina, a fin de explorar variables alternativas y proceder a regresiones de corte temporal destinadas a confirmar si las variables ya examinadas mantienen su poder explicativo a través del tiempo.

\section{Regresiones de panel: América Latina}

En el cuadro 5 se presentan las estimaciones de panel para los 18 países de América Latina (véase el cuadro 2), considerando las variables relevantes ya incluidas en el cuadro 4. Estas estimaciones se diferencian especialmente

CUADRO 5

\section{Ecuaciones para América Latina y el Caribe, 1990-2010}

\begin{tabular}{|c|c|c|c|c|}
\hline Muestra & \multicolumn{4}{|c|}{ América Latina y el Caribe (En logaritmos) } \\
\hline Variable dependiente & \multicolumn{4}{|c|}{ Coeficiente de Gini } \\
\hline Período & \multicolumn{4}{|c|}{$1990-2010$} \\
\hline Variables independientes & (1) & (2) & (3) & (4) \\
\hline
\end{tabular}

\section{Fiscales}

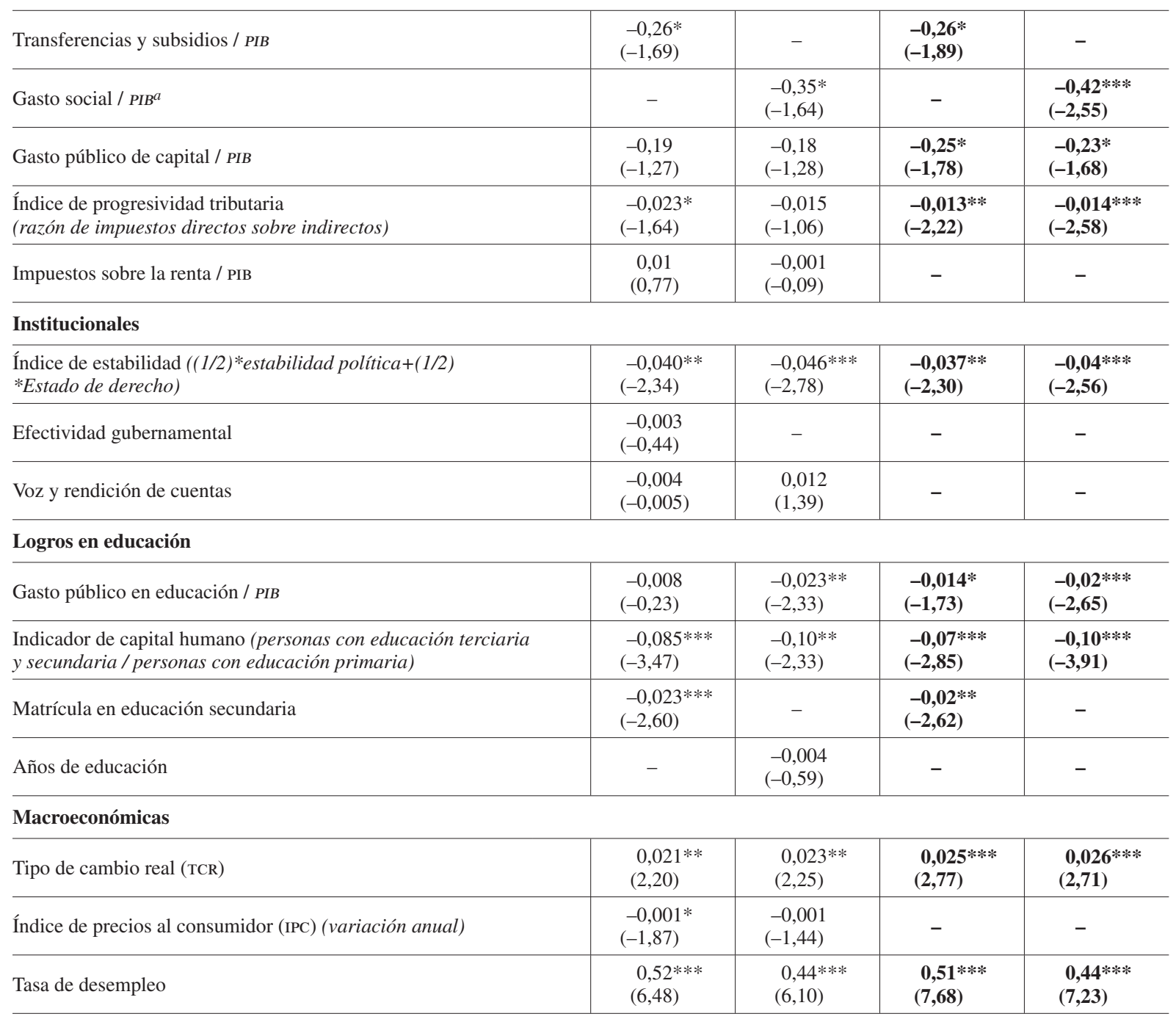


(Conclusión)

\begin{tabular}{|c|c|c|c|c|}
\hline Muestra & \multicolumn{4}{|c|}{ América Latina y el Caribe (En logaritmos) } \\
\hline Variable dependiente & \multicolumn{4}{|c|}{ Coeficiente de Gini } \\
\hline Período & \multicolumn{4}{|c|}{$1990-2010$} \\
\hline Variables independientes & (1) & (2) & (3) & (4) \\
\hline Ingreso per cápita a PPA (variación anual) & $\begin{array}{l}-0,042 \\
(-0,69)\end{array}$ & $\begin{array}{c}-0,061 \\
(-0,99)\end{array}$ & - & - \\
\hline $\mathrm{N}^{\mathrm{o}}$ de observaciones & 357 & 360 & 375 & 378 \\
\hline $\mathbf{R}^{2}$ ajustado & 0,86 & $\mathbf{0 , 8 5}$ & 0,86 & $\mathbf{0 , 8 5}$ \\
\hline
\end{tabular}

Fuente: elaboración propia.

Notas: Valores estadísticamente significativos al 1\%***, 5\%** y $10 \% *$.

a En el gasto social no se incluye el gasto en educación.

Estadístico T entre paréntesis.

PIB: producto interno bruto.

PPA: paridad de poder adquisitivo.

por los indicadores relativos a los logros en educación, siendo el indicador de capital humano (el cociente entre personas con educación secundaria y terciaria sobre las personas con educación primaria) el más relevante. Esta variable también se utiliza en las estimaciones de Cornia (2012).

En lo que se refiere a las variables fiscales, el mejor ajuste se comprueba al separar el gasto social del gasto público en educación (véase la ecuación (4) del cuadro 5). A su vez, el índice de progresividad tributaria se revela significativo en esta última ecuación, aunque con un menor coeficiente que las variables de gasto. En los gráficos 8 y 9 se puede comprobar que tanto el aumento del gasto social como el cambio en la composición tributaria permiten explicar los progresos del coeficiente de Gini en los últimos años.

Sin embargo, la tasa de desempleo es la variable que resulta significativa de manera más consistente y con un alto impacto; por cada punto de disminución de la tasa de desempleo el índice de Gini se reduce en 0,44 puntos. Sin duda, las mejoras del empleo formal y el consecuente incremento de los ingresos laborales explican buena parte de los progresos recientes (véase el gráfico 10). Como se detalla en CEPAL (2011), la descomposición de las variaciones de la desigualdad revela que el ingreso por adulto aparece como el principal factor impulsor de la mejora distributiva. En 10 países de la región, la variación del ingreso laboral explica el 90\% o más del total de estas mejoras; en otros cinco el cambio de los ingresos no laborales, esencialmente transferencias, contribuyó en un $40 \%$ o más a la merma de la desigualdad.

Si bien la descomposición mencionada ofrece una metodología contable para explicar los cambios, la estimación econométrica, a su vez, permite realzar el efecto de otras variables, como los logros en educación ya mencionados, o las institucionales. Así, el índice de estabilidad elaborado por el Banco Mundial parece tener también un efecto relevante. Si bien contrariamente a lo esperado, la tasa de inflación no pareció ser determinante en el período en estudio, la medición del tipo de cambio real sí es significativa. Una explicación es que las caídas recientes del tipo de cambio real se correlacionan con inflaciones más bajas en la región. Finalmente, el ingreso per cápita no resultó significativo, pues como se discutió en las secciones anteriores, han coexistido tendencias diversas en el período de estimación entre el nivel y la distribución del ingreso.

Las ecuaciones resumidas en el cuadro 5 presentan de este modo efectos significativos en el coeficiente de Gini. La evidencia empírica corrobora los resultados encontrados en otros estudios recientes, permitiendo ver que las políticas públicas sí afectan significativamente a la distribución del ingreso, de manera directa por medio del gasto social y la progresividad tributaria, e indirectamente mediante la calidad de la educación y de las instituciones; también subraya el papel primordial de los ingresos laborales en las mejoras recientes. En estas estimaciones, el índice de Gini inicial (o rezagado) ya no resulta significativo. 
GRÁFICO 8

América Latina y el Caribe: coeficiente de Gini y gasto social, varios períodos

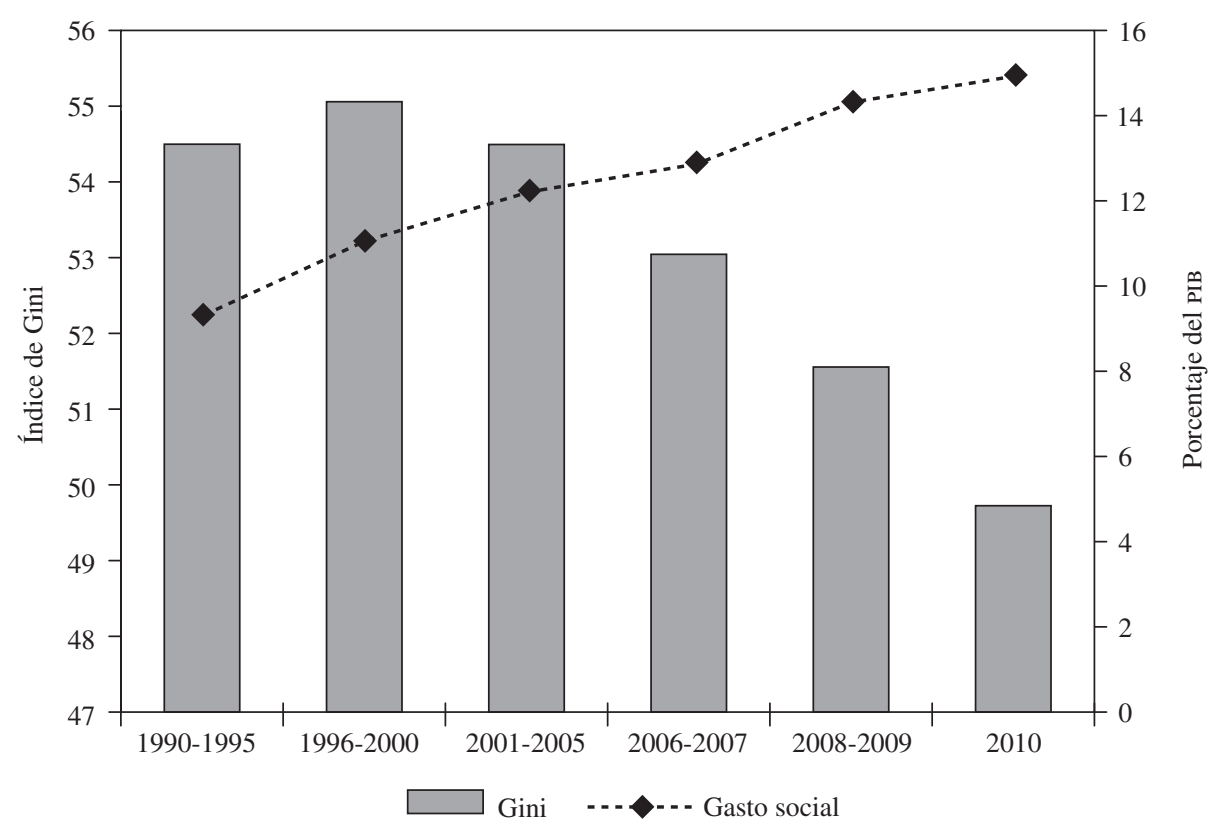

Fuente: elaboración propia.

PIB: producto interno bruto.

GRÁFICO 9

América Latina y el Caribe: coeficiente de Gini e índice de progresividad tributaria, varios períodos

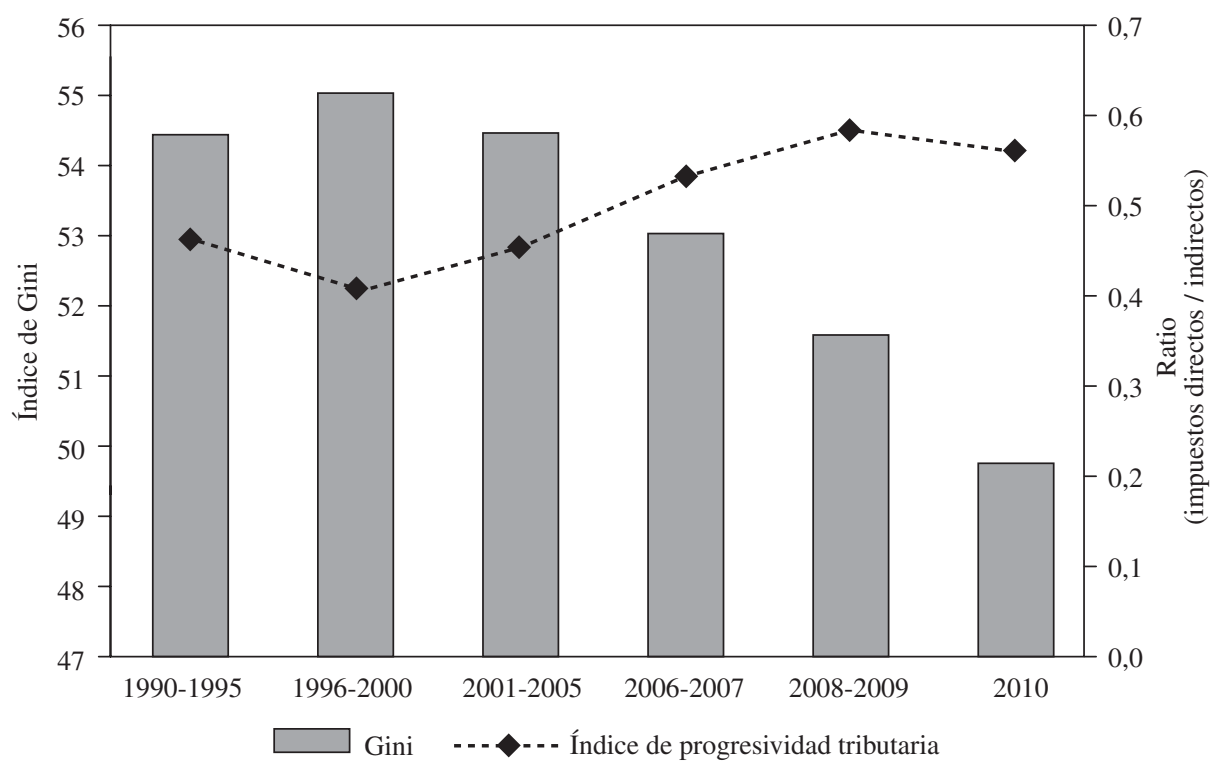

Fuente: elaboración propia. 


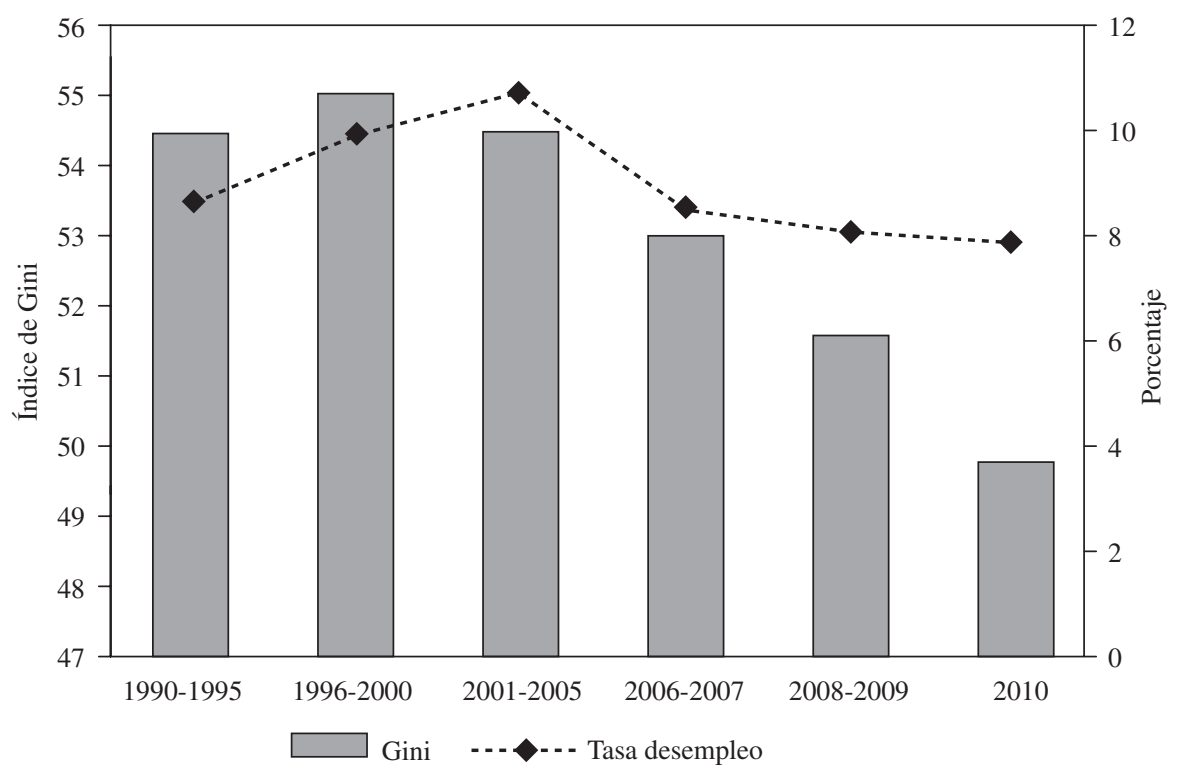

Fuente: elaboración propia.

\section{IV}

\section{A modo de conclusión: opciones para superar el "síndrome del casillero vacío"}

Sin constituir el énfasis principal, a menudo en los estudios relativos a la superación de la pobreza y la distribución del ingreso subyacen visiones encontradas sobre el papel del Estado, ya sea como un agente catalizador de la "transformación productiva con equidad" o como el principal actor de las necesarias acciones correctivas en el ámbito social. En palabras de Infante y Sunkel (2009), "sería imperioso ir complementando progresivamente las políticas redistributivas con otras de carácter distributivo, de modo de poder reducir las brechas de productividad y, por ende, mejorar el ingreso primario (autónomo) de los sectores menos favorecidos. Las políticas distributivas contribuirían así a disminuir efectivamente la desigualdad tanto de ingresos como de acceso a oportunidades entre los diversos grupos que componen la estructura social".

Para este dilema entre fomento productivo y políticas sociales resulta relevante el proverbio chino: "Regala un pescado a un hombre y le darás alimento para un día, enséñale a pescar y lo alimentarás para el resto de su vida". Sin duda, en esta disyuntiva no caben respuestas categóricas - y por lo tanto abrir una brecha entre políticas de fomento y acciones asistencialistas-, pues las experiencias de crecimiento con equidad son muy variadas, con niveles y composiciones del gasto público igualmente diversas.

Conviene resaltar que los dilemas entre crecimiento e igualdad, siempre latentes, se diluyen cuando se priorizan aquellos gastos que tienen efectos positivos en el crecimiento económico, el empleo formal y el acceso a bienes públicos. La tarea de mejorar la calidad del gasto público en América Latina y el Caribe pasa entonces por la inversión sostenida en capital físico y humano y en innovación y conocimiento (CEPAL, 2010).

En este trabajo se ha procurado identificar evidencia empírica respecto de los cambios positivos que ha registrado recientemente el coeficiente de Gini de distribución del ingreso en los países latinoamericanos. De 
esta forma, los aumentos y mejoras en el gasto público social, la educación, la inversión pública y la composición tributaria han tenido una repercusión positiva.

Asimismo, se destaca la relevancia del ciclo macroeconómico, aproximado por la tasa de desempleo, en las variaciones del índice de Gini. De todos modos, tal como es importante destacar el papel del Estado y especialmente de la política fiscal en el objetivo de desarrollo inclusivo, no lo es menos enfatizar la gravitación del sector privado en este proceso, particularmente su facultad de dinamizar la inversión y crear empleos.
Como plantea Fajnzylber (1990), "para alcanzar los dos objetivos centrales del desarrollo — la competitividad auténtica y la equidad - hacen falta muchas instituciones y muchas políticas. Pero no tendremos ni competitividad ni equidad, si no se atiende a los recursos humanos y a su educación, capacitación e incorporación al conocimiento científico y tecnológico. Hacer el discurso de la equidad, o hacer el discurso de la competitividad, o aún más, hacer simultáneamente la apuesta a ambos propósitos, y no hacer un esfuerzo consustancial y consistente en este sentido, es estrictamente poesía".

\section{Bibliografía}

Afonso, A., L. Schuknecht y V. Tanzi (2008), Income Distribution Determinants and Public Spending Efficiency, Working Paper Series, No 861, Frankfurt, Banco Central Europeo.

Banco Mundial (2006), Informe sobre el desarrollo mundial 2006: Equidad y desarrollo, Washington, D.C.

Barro, R. (2000), "Inequality and growth in a panel of countries", Journal of Economic Growth, vol. 5, № 1, Springer.

CEPAL (Comisión Económica para América Latina y el Caribe) (2011), Panorama social de América Latina (LC/G.2514-P), Santiago de Chile, noviembre. Publicación de las Naciones Unidas, $\mathrm{N}^{\circ} \mathrm{de}$ venta: S.12.II.G.6.

(2010), La hora de la igualdad: Brechas por cerrar, caminos por abrir (LC/G.2432(SES.33/3)), Santiago de Chile.

(2009), Panorama social de América Latina 2009 (LC/ G.2423-P), Santiago de Chile, noviembre. Publicación de las Naciones Unidas, $\mathrm{N}^{\circ}$ de venta: S.09.II.G.135.

(2008), La transformación productiva 20 años después. Viejos problemas, nuevas oportunidades (LC/G.2367(SES.32/3)), Santiago de Chile.

(2000), Equidad, desarrollo y ciudadanía (LC/G.2071/ Rev.1-P), Santiago de Chile. Publicación de las Naciones Unidas, $\mathrm{N}^{\circ}$ de venta: S.00.II.G.81.

(1998), El pacto fiscal. Fortalezas, debilidades, desafíos (LC/G.1997/Rev.1-P), Santiago de Chile. Publicación de las Naciones Unidas, $\mathrm{N}^{\circ}$ de venta: S.98.II.G.5.

(1990), Transformación productiva con equidad: La tarea prioritaria del desarrollo de América Latina y el Caribe en los años noventa (LC/G.1601-P), Santiago de Chile. Publicación de las Naciones Unidas, $\mathrm{N}^{\mathrm{o}}$ de venta: S.90.II.G.6.

(1964), La mano de obra y el desarrollo económico de América Latina en los últimos años (E/CN.12/L.1), Santiago de Chile.

Cornia, G. (2012), "Inequality trends and their determinants: Latin America over 1990-2011", Working Papers, No WP2012/09, Helsinki, Instituto Mundial de Investigaciones de Economía del Desarrollo.

De Ferranti, D. y otros (2004), Inequality in Latin America and the Caribbean: Breaking with History?, Washington, D.C., Banco Mundial.

Deininger, K. y P. Olinto (2000), "Asset distribution, inequality and growth", Policy Research Working Paper, $\mathrm{N}^{\circ} 2375$, Washington, D.C., Banco Mundial.

Fajnzylber, F. (1990), "Industrialización en América Latina: de la 'caja negra' al 'casillero vacío': Comparación de patrones contemporáneos de industrialización”, Cuadernos de la CEPAL, No 60 (LC/G.1534/Rev.1-P), Santiago de Chile, Comisión Económica para América Latina y el Caribe (CEPAL). Publicación de las Naciones Unidas, $\mathrm{N}^{\circ}$ de venta: S.89.II.G.5.

FMI (Fondo Monetario Internacional) (2012), World Economic Outlook. Growth Resuming, Dangers Remain, Washington, D.C., abril.
Foro Económico Mundial (2006), The Global Competitiveness Report 2006-2007, Centre for Global Competitiveness and Performance, Ginebra.

Gómez Sabaini, J.C. y R. Martner (2008), América Latina: Panorama global de su sistema tributario y principales temas de política, Santiago de Chile, Instituto Latinoamericano y del Caribe de Planificación Económica y Social (ILPES)-Comisión Económica para América Latina y el Caribe (CEPAL).

González, I. y R. Martner (2010), "Del síndrome del casillero vacío al desarrollo inclusivo: buscando los determinantes de la distribución del ingreso en América Latina", Santiago de Chile.

Infante, R. y O. Sunkel (2009), "Chile: Hacia un desarrollo inclusivo", Revista de la CEPAL, No 97 (LC/G.2400-P), Santiago de Chile.

Lerda, J.C. (2009), "El pacto fiscal visto a sus 10 años", Las finanzas públicas y el pacto fiscal en América Latina, serie Seminarios y conferencias, $\mathrm{N}^{\circ} 54$ (LC/L.2977-P), Ricardo Martner (comp.), Santiago de Chile, Comisión Económica para América Latina y el Caribe (CEPAL). Publicación de las Naciones Unidas, $\mathrm{N}^{\circ}$ de venta: S.08.II.G.86.

López, H. y L. Servén (2005), "A normal relationship? Poverty, growth and inequality", Policy Research Working Paper Series, N 3814, Washington, D.C., Banco Mundial.

Lundberg, M. y L. Squire, (2003), "The simultaneous evolution of growth and inequality", Economic Journal, vol. 113, No 487, Oxford, Royal Economic Society.

Lustig, N., L. López-Calva y E. Ortiz-Juárez (2011), "Declining inequality in Latin America: some economics, some politics", Working Paper, $\mathrm{N}^{\circ} 1118$, Tulane University.

Martorano, B. y G. Cornia (2011), The IDLA Dataset: a Tool to Analyze Recent Changes in Income Inequality in Latin America, Helsinki, Instituto Mundial de Investigaciones de Economía del Desarrollo.

Musgrave, R. y J. Buchanan (1999), Public Finance and Public Choice: Two Contrasting Visions of the State, Cambridge, Massachusetts, The MIT Press.

ocDE (Organización de Cooperación y Desarrollo Económicos) (2011), Revenue Statistics 1965-2010, París, OECD Publishing. (2010), PISA 2009 at a Glance, París, OECD Publishing. (2008), Growing Unequal? Income Distribution and Poverty in OECD Countries, París, OECD Publishing.

OCDE/CEPAL (Organización de Cooperación y Desarrollo Económicos/ Comisión Económica para América Latina y el Caribe) (2011), Perspectivas económicas de América Latina 2012: Transformación del Estado para el desarrollo, París, oECD Publishing.

Torres, M. (comp.) (2006), Fernando Fajnzylber. Una visión renovadora del desarrollo en América Latina (LC/G.2322-P), Santiago de Chile, Comisión Económica para América Latina y el Caribe (CEPAL). Publicación de las Naciones Unidas, $\mathrm{N}^{\circ}$ de venta: S.06.II.G.124. 